\title{
AHP APPLICATION IN CONTEMPORARY NEPALESE ISSUES
}

\author{
Shashi Bhattarai* \\ Development Dynamics Pvt. Ltd. \\ Kathmandu, Nepal \\ E-mail: shashibhattarai@yahoo.com \\ Prabal Sapkota \\ Hillside College of Engineering \\ Kathmandu, Nepal \\ E-mail: prabalsapkota@gmail.com
}

\begin{abstract}
The objective of the paper is to contribute Analytic Hierarchy Process (AHP) application cases in business and personal decisions. The cases are from the Nepalese context, nonetheless it is perceived that the situation prevailing in many developing countries around the world. The paper also briefly describes the approach and outcome of first ever AHP focused decision support course taught to Executive Masters in Business Administration (EMBA) students in Nepalese business school.

Six AHP application cases of contemporary decision problems are presented with AHP hierarchy. The range of application cases are in human resources and work process management in typical IT companies, individual decisions, business school selection and renewable energy issue. Overall learning in teaching process as well as impression of AHP to the young working professionals is also discussed.

The demand responsive skill development process in AHP application, based on the decision issue identified by individuals is found to be very effective way to give insight on the utility of the decision support approach. AHP is found not only effective tool of gaining the insight of a real life decision issues but also as the tool to build the holistic way of thinking while addressing the critical decision situation.
\end{abstract}

Keywords: AHP application, contemporary issues, EMBA, Nepal

\section{Introduction}

The most common application cases seen in the literature are academic exercise, the cases presented in the paper are also not an exception. The cases presented in the paper are individual perception of appropriateness to apply AHP in their professional or personal life in most recent time. The approach and outcome of first ever AHP focused decision support course taught to EMBA students in a leading business school in Nepal are discussed in the paper. The course was completed in May 2012. The small class of six students, all from technical background, working for more than three years in leading national or multinational institutions, two were working with academic institutions and rest were working with technology companies.

We will also describe briefly the course content, coverage, style and approach of going deeper in to the AHP application with real life cases perceived by the students themselves. The cases are relating to business of the institutions and professional or personal life of individuals applying AHP.

\footnotetext{
* Corresponding author would like to acknowledge Rajiv Kamacharya, Pritish Shrstha, Sanam Silparkar, Sangita Manandhar, Prabal Sapkota and Sanjay Pudasaini for their candid work on the cases presented the paper.
} 
The cases of the AHP applications presented are individual projects to six students, with five minor and one major project each. The class have generated a pool of 18 minor cases as building blocks for cases development starting from manual AHP solving exercise to start with and building up on the initial cases by adding up of complexity. The six cases are major project, with almost sixty percent of the entire three credit course. The paper concludes with overall learning process of teaching MCDM based Decision Support System in general and AHP in particular.

The Analytic Hierarchy Process (AHP) has been developed by Saaty (1980, 1982, and 1990) and is one of the best known and most widely used multi criteria approaches. It allows users to assess the relative weight of multiple criteria or multiple options against given criteria in an intuitive manner. In case quantitative ratings are not available, policy makers or assessors can still recognize whether one criterion is more important than another (Saaty 1980).

\section{Process and Learning from the teaching of AHP}

Class room based AHP teaching starting from scratch by a faculty without any class room experience was itself an adventure and learning process. The process started from the revision the course syllabus which was designed eight years back mostly focusing on the overview of decision support system targeting to MIS specializing students. The course was re-designed covering general background on decision support system, then narrowed to the multi criteria decision making followed by developing concept of MCDM and skill in the AHP application to the decision problem identified by the students themselves. Literature on teaching AHP and experience in business school was also part of learning during the teaching process, (Bodin and Gass, 2003) was among the literature referred on teaching AHP.

With the objective of developing concept of MCDM in general and imparting skills on applying AHP based MCDM; a demand responsive skills development approach of AHP teaching process was adopted. Starting from the basics of AHP theory with practice in AHP application was followed. The manual calculation on the cases of real life problem indentified by each professional EMBA students was taken up as first minor application case. The subsequent AHP application exercise were on adding up the complexities such as dealing with actors, hierarchy with more levels, skill of developing complex hierarchy, rating problem, sensitivity analysis and interpretation of the results or gaining the insights of the decision problem or issues.

Each classroom session was planned with the composition of Videos and TED Talks relating decision making from different prospective with aim to enrich and relate different viewpoints with AHP based decision support. The other component of each session was each student's talk in given topic or AHP based application journal paper. The talk was to be delivered by student in very limited time of Sixty Second, termed as Sixty Second Summary (SSS), earlier the SSS were without slide, later the talks ware to be given with Single Slide Show (SSS), so at the later stage students were giving sixty second talk with single slide (SSS with SSS). A pool of more than 50 AHP applications, mostly of recent time, ie 2009 or later application cases were collected for the students to select for later session of SSSs with SSS. By the time the students were completing their minor project, acquainting them with the cases of applications published in international journal's widen their knowledge to apply their own decision issues identified by each students in their personal or professional life. The major AHP application cases taken up by each student are discussed in detail in the following section of the paper.

As the teaching style was of more flexible and demand responsive, the students at the later stage of class session were interested to know more about the other MCDM tools which made them able to make comparative evaluation of AHP with other tools. Though, going bit detail with other method was not in 
the session plan, based on the students demand other MCDM tools like PROMITHEE, ELECTEA, Goal Programming, MAUT, SMART were also introduced in addition the initial course plan.

By the time of completing the course, including the major projects, the students had developed very good skills of AHP application and were well aware with the art and science of AHP. The students were also able to somehow compare AHP with other prominent MCDM tools.

The learning process of AHP was found to be effective, which created curiosity and insights on utility of AHP. The building block approach of teaching was found be lasting impression to the learners. It was great to know that the AHP was taken not only as effective tool of gaining the insight of a real life decision issues but also as the concept to build the holistic way of thinking while addressing the critical decision situation. It was also realized by the students that the AHP to be a MBA wide course to be introduced in a business school.

\section{Description of AHP application cases}

There were six cases of AHP application as major projects, which are discussed in the paper as AHP application cases in contemporary Nepalese issues are follows:

\subsection{Find the best way to groom IT professionals in Nepal}

In Nepal, normally computer graduates are not well accustomed to various tools and platforms required for IT companies. Courses offered by various IT schools do not meet market standards. Hence grooming is unavoidable though being highly expensive task. On top of all this, the turnover ratio of employee is very high in IT sector.

Like most of the Nepal based IT companies, the company associated with the issue also shared the common problem like: difficulties in finding experienced developers, initially unproductive fresh graduates, need of grooming, choosing proper grooming method is a difficult task. The case tries to find the better way to groom IT professionals in Nepal.

This work has been devised in such a way that with the least amount of time is consumed in a business decision problem, so the process was conducted in a group setting using AHP. The approach of addressing the issue involved two groups of stakeholders, Management team: Head of Departments \& Senior Business Project Manager and Employee: Software Programmers from Dot Net \& PHP team. Separate 30 minutes discussions were held on each team to discuss various options for grooming and factors affecting their selection. Separate one hour discussions were held with each team to evaluate alternatives using AHP.

The discussion led to primarily two types of alternatives that required attention. Grooming and Selection: on campus training (OCT), assistance on on-campus projects (ACP), availability of job oriented training courses (JOTC), pre job training (PJT), on the job training (OJT), internship (Intern).

Awareness: workshops focusing on market, opportunities and practices, software competition, sponsorship during various events, assistance on on-campus projects.

Factors related to Grooming for Employees were job opportunities (JO), value on market (VM), time required (TR), effort required (ER), skill acquired (SA), whereas for Management team the factors were: time required (TR), effort required (ER), skill acquired (SA), possibility of joining competitors (PJC), retention (Ret), targeted number of people (TNP). 
Factors affecting various alternatives for Awareness were: Effective Brand awareness, Time and Effort required, Influence on "Grooming and Hiring". The same factors hold true for all the stakeholders under consideration.

An AHP hierarchy had been developed based on the discussion as guided by (Saaty 1982, 1990). Figure 1 shows the hierarchy developed for grooming while awareness has not been considered.

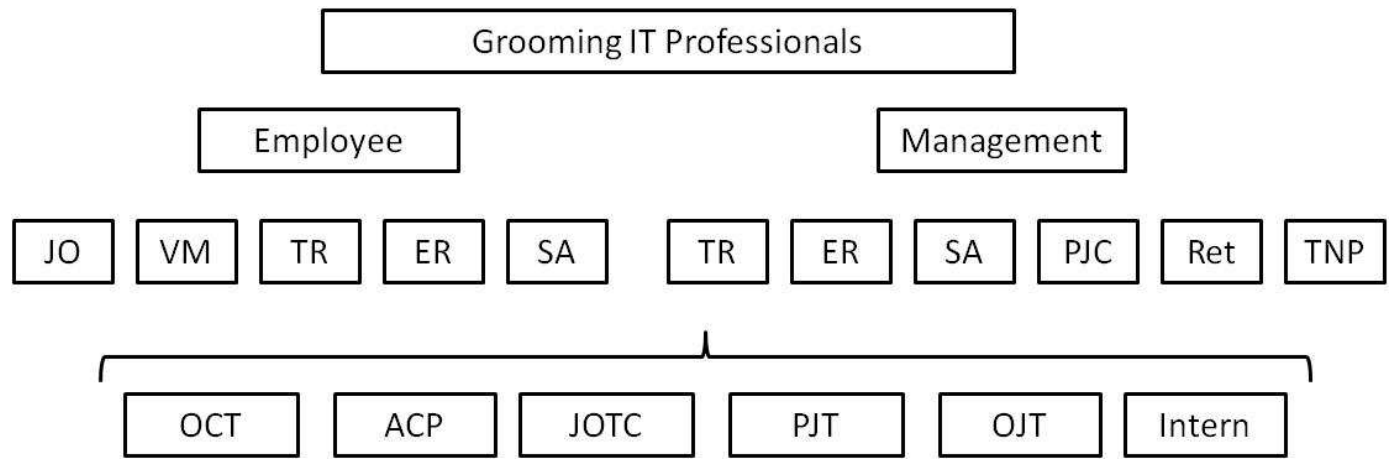

Figure 1. Hierarchy development for grooming IT professionals

The result obtained based on the opinion of both Employees and Management is presented below, according to their priority in a sequence as follows:

Employee's preference: On campus training, Assistance on on-campus projects, Internship, Pre job training, On the job training, Availability of job oriented training courses.

Management preference: Pre Job Training, On the job training, Internship, Assistance on On-campus projects, Availability of job oriented training courses, On campus training.

Based on the results, it is recommended to the IT companies to focus high on pre-job training. The companies can also be engaged on the job training and internship. Apart from this, to influence students, IT companies can be involved for on-campus projects. The result of the case reflects the best way the IT companies can influence new graduates to have the expertise they prefer in very less time, effort and cost.

\subsection{Solution for adopting change in IT project delivery}

The case is from an IT company which is the off-shoring partner in Nepal with head office in Germany. There exists a problem that finished projects are coming back for correction. The rules and regulations in place three years ago, was no longer standard and projects correct then was now incorrect and the company have to redo a lot of things.

When products of the clients get updated, it is necessary for the company to update already completed models as well. These demands of clients are forwarded to the company by head office. And to compete in the market, the product of Nepal based company need to be compatible with their emerging competitors. Around three years ago the company was sole player. But now there are many competitors. To match with competitors, the company has to update existing products even when they were originally correct. So the company was looking for the best solution to tackle this problem.

Actors identified while addressing the issue were Clients, Competitors, Head office. Similarly the Factors and Sub-factors identified were, Time: time is the major factor; Cost: Based on the cost, the head office categorizes two version of product: grob (rough) and detail; Error: (Sub factors: basic and specific). Error can be basic or specific. Basic errors can be corrected in batches. Simple errors must be corrected to maintain the standardization of objects. Specific errors are hard errors, and to be corrected object by object. 3D pdf error: (Sub factors: Real errors and pdf specific error). 
During the process, two alternatives have been identified: Update as required: This is what the company has been doing but creates a scenario of uncertainty. Set Standard: As new rules are coming, existing rules must be regularly updated and followed.

An AHP based decision hierarchy has been developed to address the process improvement and is presented in Figure 2.

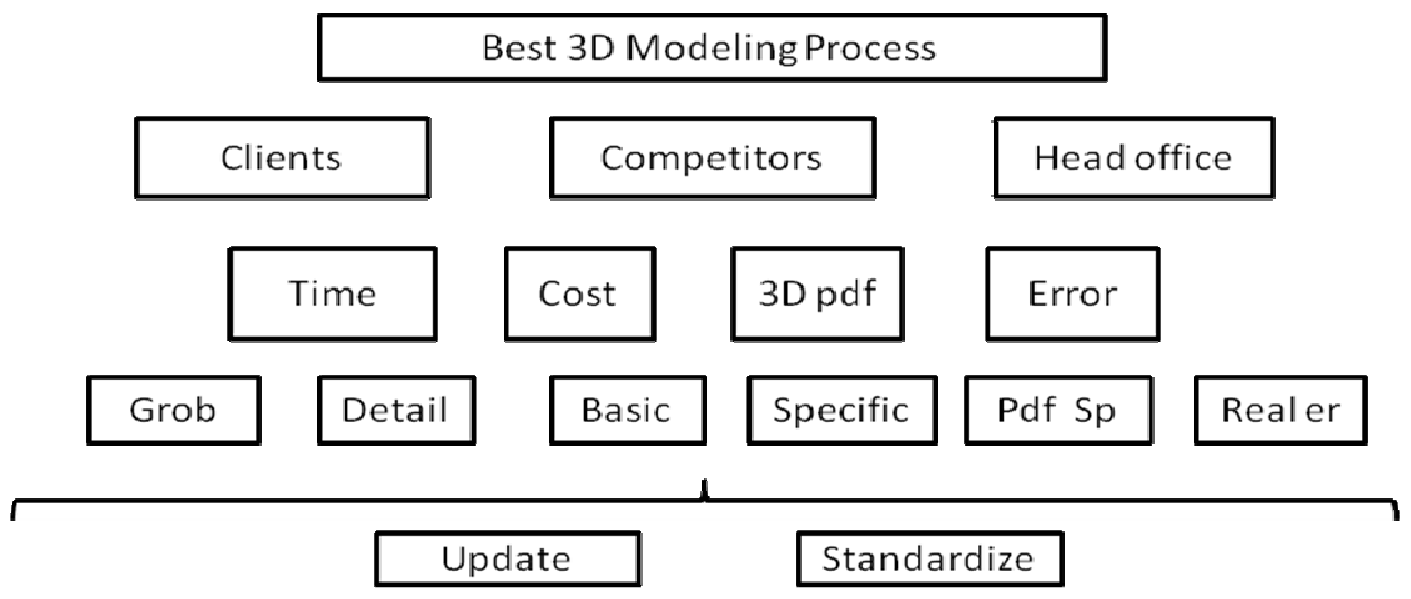

Figure 2. AHP Hierarchy adopting change in $3 \mathrm{~d}$ modeling process

The result of AHP analysis reflected that the weight on head office is seen higher (0.528) as they have to make frequent contact with them. The result was somehow unexpected because standardization $(0.55)$ won the battle but was a close one. When the influence of client was increased (89.9\%) the two alternatives received almost equal weights.

The client do not have clear preference over standardization or updating as they just want the job done in predefined price. But head office had clear preference of standardization because the price is fixed at the beginning and updating normally means additional time and effort at same price. Presence of standard procedure would reduce the time which can be invested in other running projects.

\subsection{Selection of Best Career option for young professionals}

Most of the Nepalese young generations today opt to move abroad intuitively in hope of secured future and better life ahead. The decision being such crucial that can change one's life completely. Some people's hope might be fulfilled, some people achieve more than what they had imagined of and some people gain nothing, but frustration. The case scrutinizes the decision problem and understands it in depth to help young professionals make the most suitable decision as per an individual's situation and aspirations in life. The case deals with the way to select best career option for young professionals.

As per the discussion with a group of young professionals, the following factors and sub factors have been identified:

Opportunity: ambition, next generation, risks

Finance: current income, aspired income, investment, payback, cost to be incurred

Country: political, financial, legal, infrastructure, language

Quality: leisure time, satisfaction, struggle, prestige, security

Society: social, cultural, discretion, family

Background: experience, competency, education, profession, learning abilities 
The alternatives identified were, Further study abroad, Permanent residency abroad, Jobs in Nepal and Self-employment in Nepal. Figure 3 shows the hierarchy developed during the process.

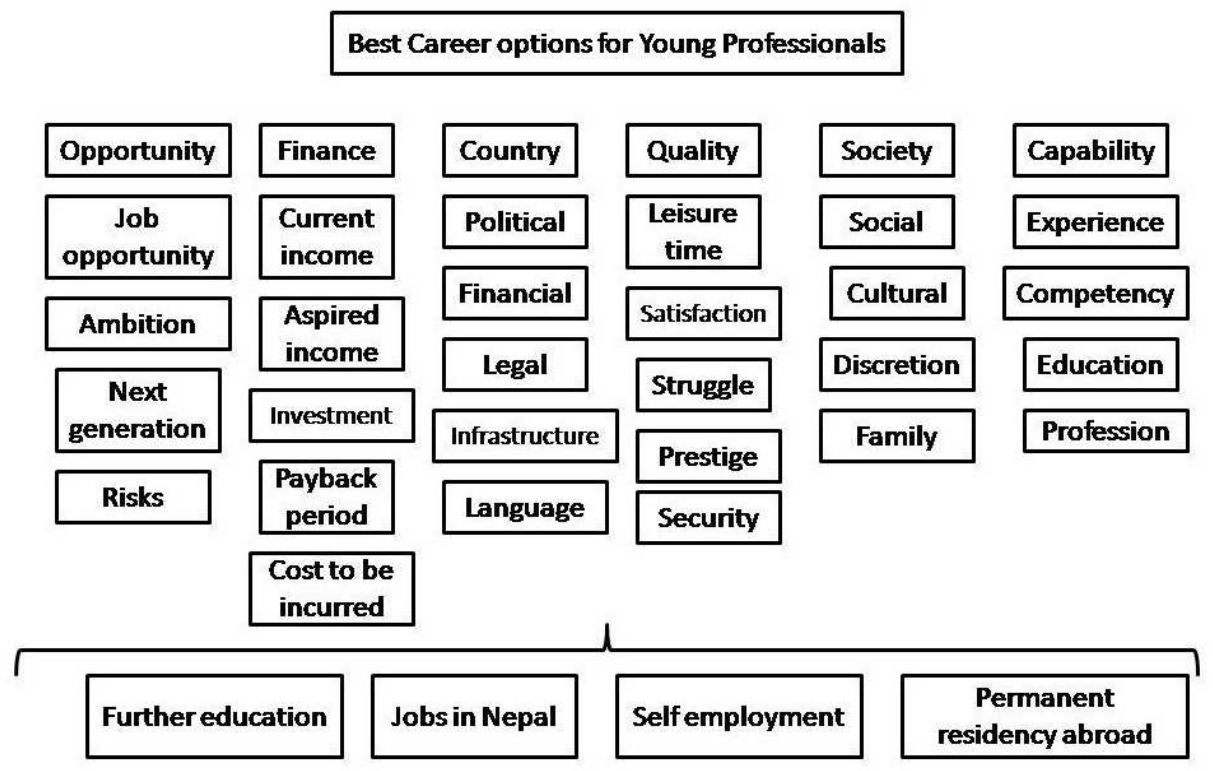

Figure 3. Hierarchy development for best career option

Once the model has been developed, three individuals who have been facing this decision problem have been offered with questionnaires and the pair wise comparison has been made. Among the three individuals, two of them have high priority on quality of life and all of the three have different alternatives to be chosen.

The decision support exercise suggested that each individual should have clear understanding of the criteria and sub criteria of their decision situation, as the criterion playing the vital role in choosing among the alternatives. The application of AHP scrutinizes the decision problem and understands it in depth to help young professionals make the most suitable decision as per an individual's situation and aspirations in life.

\subsection{Sustainable energy selection in Nepal}

The issue of global warming and immense thirst for energy that is growing on day by day basis has forced to search for new sustainable energies which can replace fossil fuels and other forms of conventional energies. Efforts have been made in search of alternative energies to compensate for the energy demand that is increasing. Further, the challenge is to develop such alternatives which not only solve the energy problems but also have positive impact on the environment.

Several researches has been done in the past regarding energy selection, energy planning and other energy related activities. Selection of energy system is not an easy task. It is definitely a case of Multi Criteria Decision Making process. Akella et al. talked about the impact of renewable energy systems on the factors like social, economical and environmental (A.K. Akella, 2009). Different researchers have adopted different methods in evaluation and selection of energy systems. Recently AHP has also been seen as popular tools among researchers. A B M Zohrul Kabir et al used AHP in selection of renewable 
energy in Bangladesh (A B M Zohrul Kabir, 2003). Similarly Joseph Daniel et al used AHP in evaluation of the Significant Renewable Energy Resources in India (Joseph Daniel, 2010).

Choosing the best energy system for the country like Nepal has always been controversial. Several criteria and hurdles (actors) become active during the process. Furthermore, the country has several options as a potential source of energy generation. This creates a problem of multi criteria decision making. The case deals with the best energy selection for Nepal.

This small research work uses the view of several people, categorized in five actor groups. The process has been utilized AHP. Five possible alternatives have been identified are Solar cell, Biodiesel (all liquid bio-fuel), Biogas, Wind energy and Nuclear energy. The factors identified were Future prospects, Socioeconomic, Environmental and Technological. The process utilized the influential actors groups identified as Donor Agency, General People, Business People, Energy Expert and Politician. An AHP hierarchy has been developed based on the above mentioned actors, factors, sub-factors and alternatives. Figure 3 shows the hierarchy developed during the process.

Sustainable energy for Nepal

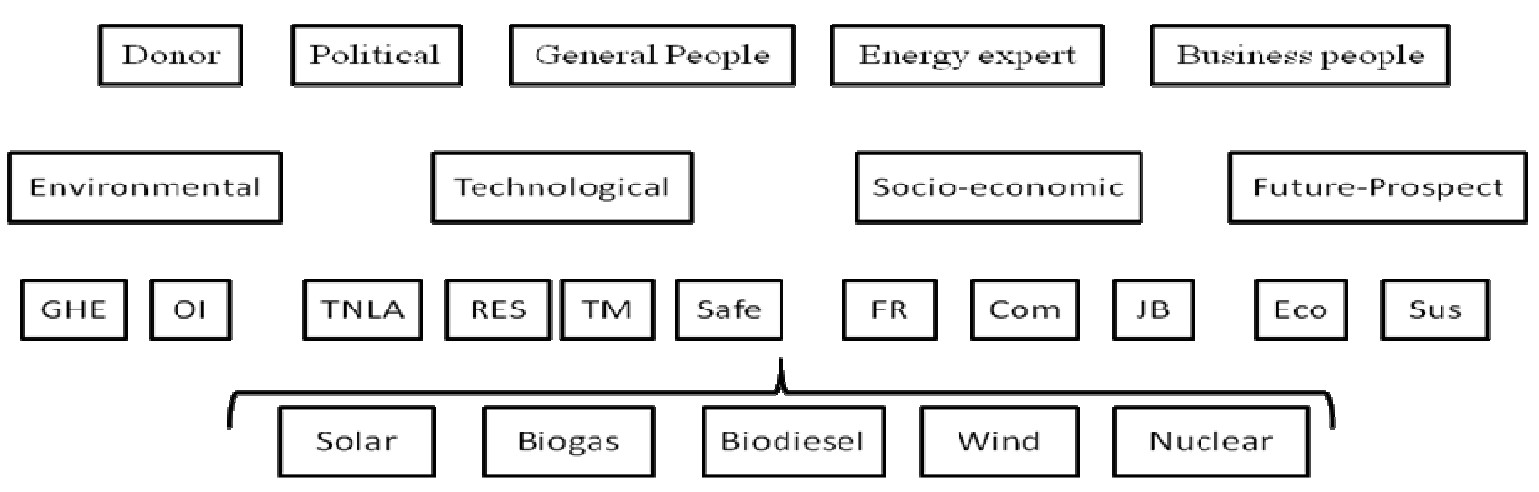

GHE: Green house emission, OI: Other impacts, TNLA: Technology known by local actors, TM: Technology maturity, RES: Resources, FR: Financial requirements, Com: Compatibility to the local and national policy, JB: Job opportunity, Eco: Economy, Sus: Sustainability

Figure 4. Hierarchy for sustainable energy for Nepal

The overall result shows that Biogas should be the sustainable energy for Nepal followed by Solar energy and the third one is Liquid bio-fuel. Politician has been given the highest priority of $66.7 \%$ followed by donor with $16.7 \%$; remaining have equal preferences of $5.6 \%$. The scenario when energy expert has given major priority of $66.0 \%$, Liquid bio-fuel (biodiesel) becomes the first choice followed by Biogas.

The study shows that in the country like Nepal, politics should be considered as a major hurdle during the development of energy system. The result shows that development of Biogas is consensus option and should given high priority. The result remains unchanged even after removal of the actors. Nepal should also focus on the development of alternatives to fossil fuels.

\subsection{Selecting best business school in Nepal}

The case of AHP application focuses on the selection of business school for MBA program from student perspective. Choosing the right MBA school is a matter of personal preference that typically encompasses 
a desire for the pursuit of academic excellence. If the student is looking to pursue an MBA degree, it is important to consider some very specific criterion best on one's own preferences.

Some of the important factors and sub factors identified during the process are listed below.

Academic: curriculum, faculties, teaching methodology, admission process and research degree

Infrastructure: teaching, information and communication technology (ICT) and research, non academic factors

Reputation: brand name of the university, brand name of the school, prestige

Career prospect: placement record, student care, market acceptance, entrepreneurial skill

Financial: cost of study, financial support, method of payment

Other: autonomy, networks, rules and regulation.

The alternatives selected were some of the well-known business schools of Nepal offering MBA which are listed below:

Apex College (APEX), Kathmandu University School of Managemnt (KUSOM), South Asian Institute of Management (SAIM), Trivhuwan University MBA (TUMBA), White House MBA (WHBS).

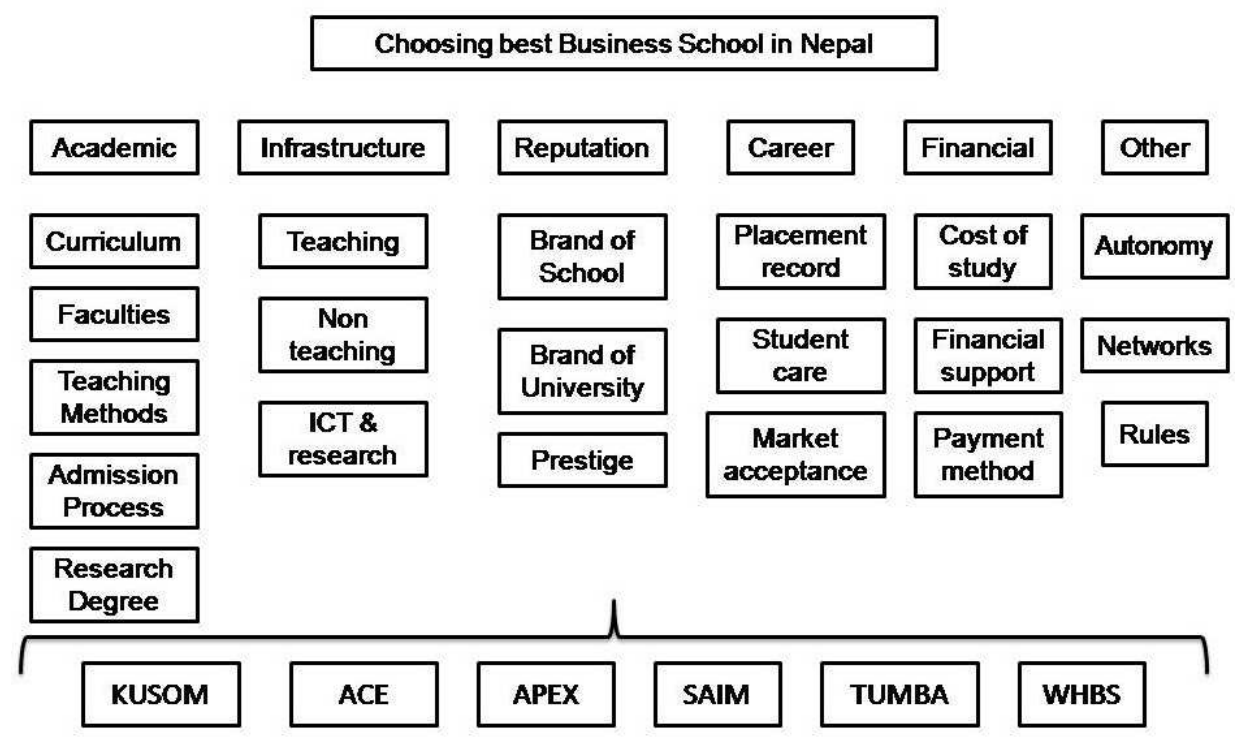

Figure 5. AHP Hierarchy for school selection for MBA

Result of the AHP based analysis with the prospective MBA students shows that the students were more concern about their career. The second concern to them was the reputation of the school. KUSOM was the first choice of Nepalese students followed by ACE and APEX. The case clearly reflected several issues regarding the student's choice of factors influencing their decision while choosing MBA schools. Student gave $35 \%$ priority to career prospects. The case is in line with the statement "the choice of any school by the student depends entirely on the student inclination to a particular preference and the requirements" Çetgn \& Adiguzel (2010).

\subsection{Post High School (after Grade 10) Field of Study Selection}

The AHP application case deals with the confusion associated with the decision of career or future plan for the School Leaving Certificate (SLC) graduating students. The decision problem addressed was which stream of higher study to take, i.e. Science, Management or Humanity. For many students, the decision is very crucial and confusing, involving multiple actors, conflicting factors. The case is dealt with two 
actors, first Student himself/herself and second Family of the student (the case utilized parent of the student).

Following factors were considered:

Personal: Students personal taste, interest, friends and relatives are considered under this factor

Time: Time required for completing the stream of study

Cost: Cost required for completion till graduation

Ease: Perceived easiness of the faculty.

Income: Income and future security expected from the faculty

Diversity: Future prospect and diversity expected in the faculty

The available alternatives with the students are Science, Management and Humanity

The intermediate alternatives considered are:

Foreign Countries: the possibility to go to foreign countries and stay there

Business: Join family business or start own business

Management: Make career in management or job in managerial post in some organization

Medicine: Become a medical doctor

Computer: Be a computer professional or work in IT field

CA: Become a Chartered Accountant

Law: Be a Lawyer or to work in Law field

Engineer: Become an engineer or work in engineering profession

The hierarchy developed during the process is shown in figure 6 .

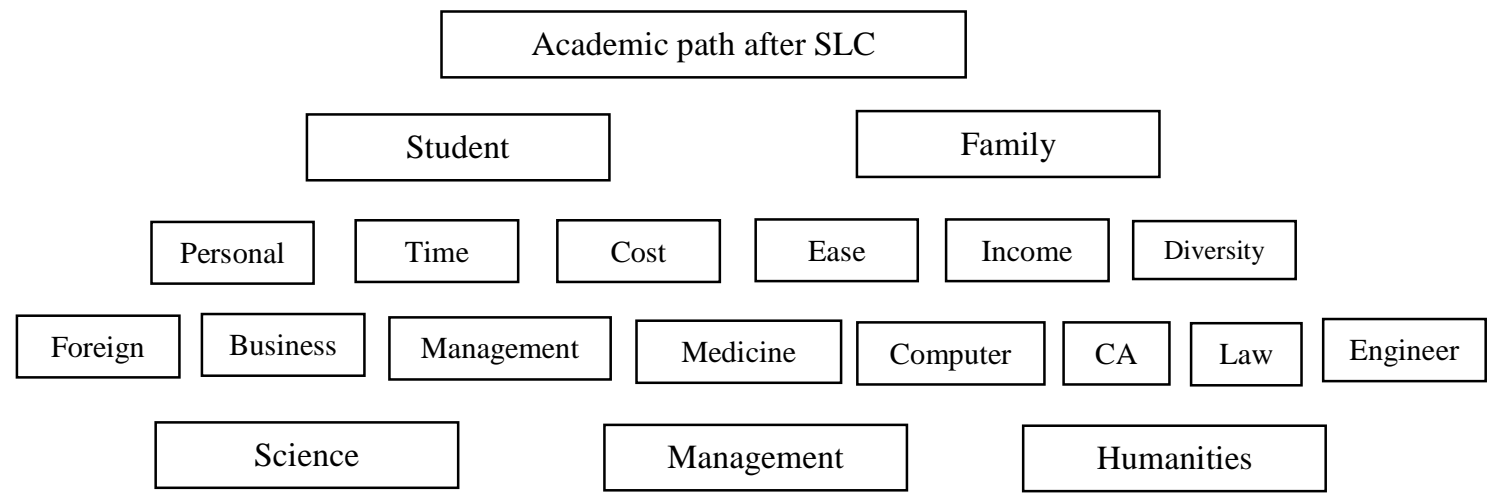

Figure 6. The AHP Hierarchy for selection of faculty after Grade X

The intermediary alternatives pave the path to the ultimate objectives, like specific professional objective for the decision maker in the longer term, including whether to serve the home country or to settle in foreign land or to start own business or to become professional job seeker.

The AHP based decision support framework was applied to typical student just graduated from Grade Ten. In the analysis, we found that the case students gave more priority to income after graduation whereas for family, income is important but cost of going to particular stream of faculty also plays a vital role. The assessment resulted that the Science faculty was highly preferred; Management was in the second position. The sensitivity analysis indicated, if weight to the cost to study particular faculty increased, then best alternative was changed to Management from Science and Humanity was always in the last preference.

In conclusion, the case applied is found highly helpful in developing the student and parent's confidence as well as resolve the conflict with the stakeholders involved in the decision making process. This framework of decision support to guide the students in giving insights to the decision problem of their 
life, so that they are not left with any regret in future, as the very popular saying goes "Time is very precious and never comes back". The framework is found to be very useful to college counseling desk officials to help student and their parent to choose the appropriate faculty to take for the future studies.

\section{The Concluding Remarks}

Observation and leanings out of the process of sharing knowledge in AHP application and working with real life decision issues with young professionals are presented in the bullet point as follows:

- Young professionals have highly recommended AHP to be included among the required course for the E/MBA, minimum with two credit hours

- The demand responsive AHP application skill development process, based on the decision issue identified by individual learner was found to be very effective way to give insight of the utility.

- AHP is taken not only as effective tool of gaining the insight of a real life decision issues but also as the concept to build the holistic way of thinking while addressing the critical decision situation.

\section{REFERENCES}

A B M Zohrul Kabir, S. M. (2003). Selection of Renewable Energy Sources using Analytic Hierarchy Process. Proceedings of ISAHP 2003 (pp. 267-276). Bali, Indonesia.

A.K. Akella, R. S. (2009). Social, economical and environmental impacts of renewable energy systems Renewable Energy. Renewable Energy, vol. 34, pp 390-396.

Bodin, Lawrence, S. I. Gass (2003). On teaching the analytic hierarchy process, Computers \& Operations Research, Vol. 30 pp 1487-1497

Çetgn, A. C., \& Adiguzel, O. (2010). The Determination of University Selection Based Upon Analytic Hierarchy Process. Proceedings of International Symposium on Sustainable Development. Sarajevo.

Joseph Daniel, N. V. (2010). Evaluation of the Significant Renewable Energy Resources in India Using Analytical Hierarchy Process. Berlin Heidelberg: Springer Physica-Verlag.

Saaty, T. L. (1980). The Analytic Hierarchy Process. New York: McGraw Hill.

Saaty, T. L. (1982). Decision Making for Leaders: The Analytical Hierarchy Process for Decisions in a Complex World, revised edition 2008, RWS Publications, Pittsburgh, USA

Saaty, T. L. (1990). Multicriteria Decision Making, The Analytic Hierarchy Process: Planning, Priority Setting, Resource Allocation, RWS Publications, Pittsburgh, USA 